\title{
RAILWAY BALLAST CONDITION ASSESSMENT USING GROUND-PENETRATING RADAR - AN EXPERIMENTAL, NUMERICAL SIMULATION AND MODELLING DEVELOPMENT
}

Andrea BENEDETTO ${ }^{1}$, Fabio TOSTI ${ }^{2}$, Luca BIANCHINI CIAMPOLI ${ }^{1}$, Alessandro CALVI ${ }^{1}$, Maria Giulia BRANCADORO ${ }^{1}$, Amir M. ALANI $^{2}$

${ }^{1}$ Department of Engineering, Roma Tre University, Via Vito Volterra 62, 00146, Rome, Italy

e-mail: andrea.benedetto@uniroma3.it; luca.bianchiniciampoli@uniroma3.it; alessandro.calvi@uniroma3.it; mariagiulia.brancadoro@uniroma3.it

${ }^{2}$ School of Computing and Engineering, University of West London (UWL), St Mary's Road, Ealing, London W5 5RF, UK

e-mail: Fabio.Tosti@uwl.ac.uk (*Corresponding author); Amir.Alani@uwl.ac.uk

This paper reports on the GPR-based assessment of railway ballast which was progressively "polluted" with a fine-grained silty soil material. It is known how the proper operation of a ballast track bed may be undermined by the presence of fine-grained material which can fill progressively the voids between the ballast aggregates and affect the original strength mechanisms. This occurrence is typically defined as "fouling". To this effect, a square-based methacrylate tank was filled with ballast aggregates in the laboratory environment and then silty soil (pollutant) was added in different quantities. In order to simulate a real-life scenario within the context of railway structures, a total of four different ballast/pollutant mixes were introduced from $100 \%$ ballast (clean) to highly-fouled $(24 \%)$. Ground-penetrating radar (GPR) systems equipped with different air-coupled antennas and central frequencies of $1000 \mathrm{MHz}$ and $2000 \mathrm{MHz}$ were used for testing purposes. Several processing methods were applied in order to obtain the dielectric permittivity of the ballast system under investigation. The results were validated using the "volumetric mixing approach" (available within the literature) as well as by performing a numerical simulation on the physical models used in the laboratory. It is important to emphasize the significance of the random-sequential absorption (RSA) paradigm coupled with the finite-difference time-domain (FDTD) technique used during the data processing. This was proved to be crucial and effective for the simulation of the GPR signal as well as in generating synthetic GPR responses close to the experimental data. 
keywords: ground-penetrating radar, GPR, railway ballast; ballast fouling; volumetric mixing formula; random-sequential adsorption paradigm; finite-difference time-domain (FDTD) simulation; gprMax

\section{INTRODUCTION}

The structure of a traditional railway is typically constituted of steel rails fastened to the sleepers, and laid on a coarse rocky material, i.e., the ballast. Railway ballast can be defined as a homogeneously graded material coming from the crushing of hard rocks or, seldom, of coarse gravel with small-sized particles sieved out. A railway track bed structure made of ballast aggregate particles is typically laid on the subgrade directly. In some configurations, a filter layer between the ballast and the subgrade, i.e., the sub-ballast, is also included. This is manufactured by smaller-sized soil materials, such as sand or gravel. Typically, the thickness of a track bed structure ranges between $0.45 \mathrm{~m}$ and $0.75 \mathrm{~m}$. From a structural and operational point of view, the ballast/sub-ballast system accomplishes the tasks of dissipating the vertical, lateral and longitudinal stresses induced by the loads (i.e., trains passing on the rails), and draining the meteoric water by means of the high percentage of air-filled voids [1].

The proper operation of a ballast track bed is ruled by the friction between the aggregate particles, which in turn is granted by their own angularity. This strength mechanism may be undermined by the presence of finegrained material which can fill progressively the voids between the ballast aggregates. This occurrence is typically defined as "fouling" and may be related to three main factors, i.e., i) the segregation of the ballast aggregates under load, ii) the production of metal dust from the wheel/rail contact and iii) the rise of finegrained materials from the subgrade by means of capillary actions. This last factor affects greatly the strength properties of the entire railway track bed, mostly in the case of clayey soil material which flows from the foundation level [2].

Although the modern railroads are provided of geotextiles between the ballast layer and the subgrade to avoid fouling in the rail track bed, most of the dated railway asset was not purposely designed and it is affected by this occurrence. Above certain levels, the ballast fouling can involve several issues such as the loss of regularity of the rails (reduction of the train speed) and the instability of the rail track (potential derailments). Thereby, an early-stage assessment of fouling is a crucial task for railway managers in order to minimize the costs of maintenance and the risk of accidents. This concern implies a routine assessment of the geometric, physical 
and mechanical properties of the ballast/sub-ballast system and, accordingly, the effective detection of fouling. This operation is carried out traditionally in the laboratory environment according to international standard test methods [3-12]. It is extremely time-consuming, although the information retrieved are highly reliable. Similarly, the collection of ground-truth data by digging test pits has drawbacks in terms of time-efficiency and data representativeness. In view of the above, the use of time-efficient and cost-effective technologies may be an added value within the context of the effective management of railway infrastructures.

Within this framework, ground-penetrating radar (GPR) represents an extremely powerful tool, which is being increasingly used for the rapid and non-intrusive assessment and health monitoring of railways. This method relies on the electromagnetic (EM) theory and it has found major application in differing areas, such as civil and environmental engineering [13], archaeology [14], planetary explorations [15] and forensics [16]. According to Roberts et al. [17], the first GPR application in railway engineering dates back to 1985 [18] and involved the use of a low-frequency antenna system mounted over the interaxis of the rails. The low resolution of the system caused uncertainty in the interpretation of the results; thereby, later applications have focused more on the use of higher frequency antenna systems [19-21]. Several GPR-based models for the assessment of the railway ballast condition and prediction of fouling can be found in the literature [22-24]. These models are mostly based on the processing of the actual GPR data collected in the real life/laboratory environment. In this paper, differing configurations of ballast/fine-grained pollutant mixes were first evaluated electromagnetically in the laboratory environment using different signal processing techniques. Subsequently, a numerical-simulation-based methodology was introduced for the validation of the results.

It is important to emphasize on the relevance of the proposed methodology in terms of the efficiency in the investigation of the railway ballast conditions. Indeed, the complex own nature and the highly variable physical-mechanical conditions of the railway ballast aggregates within a rail track bed may require the use of specialist antenna frequencies in combination with dedicated signal processing techniques. Within this context, the use of the simulation may provide valuable support in the interpretation of the fouling process. The thorough assessment of the main geometric, mechanical, and physical properties of the ballast and the pollutant material carried out in the laboratory, represented a comprehensive source of ground-truth data for the calibration and the validation of the proposed methodology. Information such as the grain size of the particles, the mineralogy and the compaction rate between the aggregates allowed to reproduce effectively the numerical 
simulation domain of the rail track bed as well as reliable validation of the results. In addition, the use of differing antenna systems and frequencies of investigation allowed to demonstrate the actual applicability of the discussed methodology as well as to select antenna frequencies suited for the purpose.

\section{OBJECTIVES AND METHODOLOGIES}

This paper reports on the EM assessment of railway ballast in both clean and fouled conditions using different signal processing methods. A new numerical simulation methodology was also introduced. Four configurations of ballast aggregate particles and pollutant fine-grained silty soil material were manufactured within a squarebased methacrylate tank representing a railway track bed structure. At each step of the fouling process, the data were collected using several GPR systems equipped with different air-coupled antennas and central frequencies of $1000 \mathrm{MHz}$ and $2000 \mathrm{MHz}$. Various processing methods were performed for the computation of the dielectric permittivity of the ballast system. The results were obtained by using several models available in the literature. In addition, a new numerical simulation methodology based on the combination of the randomsequential adsorption (RSA) and the finite-difference time-domain (FDTD) paradigms is discussed. The remainder of this paper is organized as follows. In Section 3, the EM basics and the main working principles behind the GPR technique are discussed. Section 4 describes the experimental design, the laying out of the laboratory setup, and the main standard test methods followed for the assessment of the main geometric, physical and mechanical properties of the investigated materials. The results of the GPR surveys are presented in Section 5, where the values of the relative dielectric permittivity achieved by the time-domain signal picking (TDSP) technique, the surface reflection method (SRM) and the volumetric mixing formula (VMF) approaches within the various scenarios are compared each to one another. The outcomes of the aforementioned simulation-based methodology using the $1000 \mathrm{MHz}$ antenna frequency are therefore analysed. Conclusions and future perspectives are discussed in Section 6.

\section{THE GPR METHOD}

GPR is a geophysical non-destructive technique based on the transmission of an EM impulse towards a generic surface and the reception of the back-reflected signal. When the EM wave tackles an electric discontinuity 
(e.g., the interface between two geological formations or road pavement layers), part of the energy gets reflected, whereas the remaining part gets transmitted and travels throughout the material before being absorbed. Therefore, it is possible to retrieve information non-destructively about the subsurface by the interpretation of the back-reflected signal.

From a theoretical point of view, the EM behaviour of the surveyed material is ruled by its dielectric and magnetic properties, i.e., the relative dielectric permittivity $\varepsilon$, the electric conductivity $\sigma$, and the magnetic permeability $\mu$ [25]. In more detail, the values of $\varepsilon$ and $\sigma$ greatly influence the velocity and the attenuation of the wave propagation, respectively, whereas $\mu$ does not affect the EM behaviour in the case of non-magnetic targets.

With regard to the case of a multi-phase material (such as the ballast aggregate/air mix in a railway track bed), the overall EM behaviour is influenced by the dielectric properties of each phase. In particular, as the air and the free water components represent opposite edge values in terms of conductivity and permittivity, their rates within the mixed material affect highly the overall dielectric behaviour of the multi-phase medium. In view of this, the grain size distribution and the void index of the mix are crucial at determining the values of the dielectric parameters, as they are directly related to the presence of air and free water.

With regard to the hardware structure of a pulsed GPR system, it is broadly constituted by a control unit generating a fixed EM impulse and one or more antennas containing the transmitter $(\mathrm{Tx})$ and the receiver $(\mathrm{Rx})$ units. A radar system is configured as mono-static when a unique antenna operates as both Tx and Rx. In the case of separated Tx and Rx, the GPR system is defined as bi-static. In addition, the GPR systems can be sorted in ground-coupled and air-coupled according to the type of antenna. In ground-coupled systems, the antenna is directly in contact with the ground and allows a deeper penetration in the medium. Central frequencies available for this configuration usually range from $80 \mathrm{MHz}$ to $2000 \mathrm{MHz}$. In the case of air-coupled systems, the antenna is typically kept at a constant height above the surface, which can range from $0.15 \mathrm{~m}$ to $0.50 \mathrm{~m}$. The most common air-coupled GPR systems are pulsed systems operating in the range $500 \div 2500 \mathrm{MHz}$, with a central frequency typically of $1000 \mathrm{MHz}$. The resolution of the collected signal and the depth of the signal penetration mainly depend on the frequency of investigation.

Applications of GPR in railway engineering are typically performed using air-coupled radar systems and central frequencies between $500 \mathrm{MHz}$ and $2500 \mathrm{MHz}$ [26]. 


\section{EXPERIMENTAL FRAMEWORK}

\subsection{Experimental design}

The experimental design was aimed at assessing the main geometric, mechanical, physical, and the EM properties of the investigated railway ballast and the pollutant soil material using traditional standard test methods and differing GPR antenna systems. To this purpose, a laboratory setup was developed at the Department of Engineering of Roma Tre University, Rome, Italy. A methacrylate tank with dimensions reproducing a typical railway ballast layer (full scale) was filled up with limestone-derived ballast, with a growing percentage in weight of pollutant material. At each pollution level, GPR tests were carried out by using the available set of air-coupled antenna systems in order to investigate the influence of fouling on the EM behaviour of the reproduced ballast layer.

\subsection{Materials: assessment of the main geometric, mechanical, and physical properties}

The assessment of the main geometric, mechanical, and physical properties of the investigated materials was performed in compliance with three principal objectives: i) classifying and verifying the consistency of these materials with the main international standards and regulations of laying out in railway track beds, ii) assessing and controlling the geometric, mechanical, and physical properties of the ballast aggregates which can be relevant in EM inspections and iii) ensuring the repeatability of the tests for future comparisons of the results.

\subsubsection{Railway ballast}

Limestone aggregates typically employed for the construction of ballasted railroads were used for testing purposes. Within the international scenario of standards and practices in the field, the EN 13450:2002/AC:2004 standard [3] is the principal benchmark at the European level. The standard requires a comprehensive amount of information about the geometric, mechanical and physical properties that the railway ballast layer must comply with in a rail track bed. The most relevant parameters considered in this standard were selected herein and the corresponding standards were followed to assess the investigated material in terms of particle size distribution [4], content of fine particles [4], particle length [3] and shape index [5], resistance to fragmentation [6] and particle density [7]. Further mechanical and physical properties relevant to the interpretation of the 
results, such as the content of voids [8] and water [9], were also evaluated. Both of these latter parameters have a key role in affecting the value of the relative dielectric permittivity of a multi-phase medium. This is much more evident in the case of coarse-grained material, such as the railway ballast, where the index of voids is a relevant component. The values found for all the above parameters are listed in Table 1.

Table 1 Geometric, mechanical, and physical properties of the ballast aggregates assessed in the laboratory environment.

\begin{tabular}{|c|c|c|c|c|c|c|}
\hline \multicolumn{2}{|c|}{ Ballast property } & \multicolumn{2}{|c|}{ Regulation } & $\begin{array}{c}\text { Reference } \\
\text { unit }\end{array}$ & Value & Class \\
\hline \multirow{4}{*}{ Geometric } & Grain size & \multirow{6}{*}{$\begin{array}{c}\text { EN } \\
13450: 2013 \\
{[3]}\end{array}$} & $\begin{array}{c}\text { EN 933-1:2012 } \\
{[4]}\end{array}$ & $\begin{array}{c}\% \text { passing vs. } \\
\text { sieve size } \\
\begin{array}{c}(\mathrm{mm}): 80-63 \\
-50-40-31.5 \\
-22.4\end{array}\end{array}$ & $\begin{array}{c}100-100-79.9 \\
-30.6-1.2- \\
0.3\end{array}$ & A \\
\hline & $\begin{array}{l}\text { Fine particles } \\
\text { content }\end{array}$ & & $\begin{array}{c}\text { EN 933-1:2012 } \\
{[4]}\end{array}$ & $\begin{array}{l}\text { \% passing vs. } \\
\text { sieve size } \\
(\mathrm{mm}): 0.063\end{array}$ & 0.5 & A \\
\hline & Particle length & & $\begin{array}{c}\text { EN 933-4:2008 } \\
{[5]}\end{array}$ & $\%$ & 5.5 & B \\
\hline & $\begin{array}{l}\text { Shape index } \\
-S I-\end{array}$ & & $\begin{array}{c}\text { EN 933-4:2008 } \\
{[5]}\end{array}$ & $\%$ & 20.0 & $S I_{20}$ \\
\hline \multirow{4}{*}{$\begin{array}{c}\text { Mechanical } \\
\& \\
\text { physical }\end{array}$} & $\begin{array}{l}\text { Resistance to } \\
\text { fragmentation } \\
-L A_{R B}-\end{array}$ & & $\begin{array}{c}\text { EN 1097-2:2010 } \\
{[6]}\end{array}$ & $\%$ & 20.0 & $L A_{R B} 20$ \\
\hline & $\begin{array}{l}\text { Particle density } \\
-\rho_{s}-\end{array}$ & & $\begin{array}{c}\text { EN 1097-6:2013 } \\
{[7]}\end{array}$ & $\mathrm{g} / \mathrm{cm}^{3}$ & 2.8 & I \\
\hline & $\begin{array}{c}\text { Percentage of voids } \\
-\varphi-\end{array}$ & \multicolumn{2}{|c|}{$\begin{array}{c}\text { EN 1097-3:1998 } \\
{[8]}\end{array}$} & $\%$ & 39.0 & I \\
\hline & $\begin{array}{c}\text { Water content } \\
-w-\end{array}$ & \multicolumn{2}{|c|}{$\begin{array}{c}\text { CEN ISO/TS 17892-1:2005 } \\
{[9]}\end{array}$} & $\%$ & 0.2 & l \\
\hline
\end{tabular}

With regard to the geometric properties, the grain size of the ballast was classified as the finest-grained class out of the six identified by the EN 13450:2002/AC:2004 standard [3], i.e., class A within the main category of the aggregate dimensions $31.5 \mathrm{~mm} \div 50 \mathrm{~mm}$. The content of fine particles passing the $0.063 \mathrm{~mm}$ sieve size was calculated according to the sieving procedures described in the EN 933-1:2012 standard [4]. This parameter turned out to be equal to $0.5 \%$; hence, it fell within very low values. Tests for the classification of the particles length [5] returned an amount of $5.5 \%$ by weight of aggregates with length $\geq 100 \mathrm{~mm}$. To this effect, 40kg of ballast material were sampled. The shape index SI was evaluated according to the EN 9334:2008 standard [5] as follows:

$$
S I=\left(M_{2} / M_{1}\right) \times 100
$$


where $M_{l}$ is the weight of the whole ballast sample [g], made of minimum 100 aggregates, and $M_{2}$ is the weight of the non-cubic ballast samples [g] (i.e., where the ratio between the particle length $L$ and the particle thickness $E$ is greater than 3). This index was found to be $20 \%$, thereby proving an average amount of too long particles as well as an average level of heterogeneity in the aggregate particle shapes of the ballast.

With regard to the assessment of the main mechanical and physical properties, two further parameters are provided in the EN 13450:2002/AC:2004 standard [3]: the resistance to fragmentation $L A_{R B}$ and the particle density $\rho_{s .}$ The technical procedures for the above standards are described within the EN 933-4:2008 [5] and the EN 1097-6:2013 [7] documents, respectively. The resistance to fragmentation was assessed by the Los Angeles test method using the relevant equipment indicated in the EN 1097-2 standard [6] and following the changes to the test method included in the EN 13450:2002/AC:2004 standard [3]. This was due to the larger grain size of the ballast aggregates with respect to the fine-grained soil material which is usually tested by this method. The Los Angeles abrasion index $L A_{R B}$ was evaluated as follows:

$$
L A_{R B}=\frac{10000-m}{100}
$$

where $m[\mathrm{~g}]$ measures the mass of material segregated, as indicated by Eq. (3):

$$
m=\left(m_{50 \div 31.5}\right)_{10 \text { kg_B }}-\left(T_{1.6}\right)_{A}
$$

being $\left(m_{50 \div 31.5}\right)_{10 g_{\_} B}$ the $10 \mathrm{~kg}$ mass of the material sieved before running the Los Angeles test with grain size comprised between $31.5 \mathrm{~mm}$ and $50 \mathrm{~mm}$, and $T_{1.6}$ the material retained on the $1.6 \mathrm{~mm}$ sieve, after running the Los Angeles test. The $L A_{R B}$ index turned out to be $20 \%$ (i.e., $L A_{R B} 20$ ).

The particle density $\rho_{s}$ was evaluated according to both the wire basket (Fig. 1) and the pycnometer methods for, respectively, the aggregate particles passing the $63 \mathrm{~mm}$ test sieve and retained on the $31,5 \mathrm{~mm}$ test sieve, and the aggregate particles passing the $31.5 \mathrm{~mm}$ test sieve and retained on the $4 \mathrm{~mm}$ test sieve. An average value of $2.8 \mathrm{~g} / \mathrm{cm}^{3}$ was found, in line with the literature reference on limestone ballast stones. 

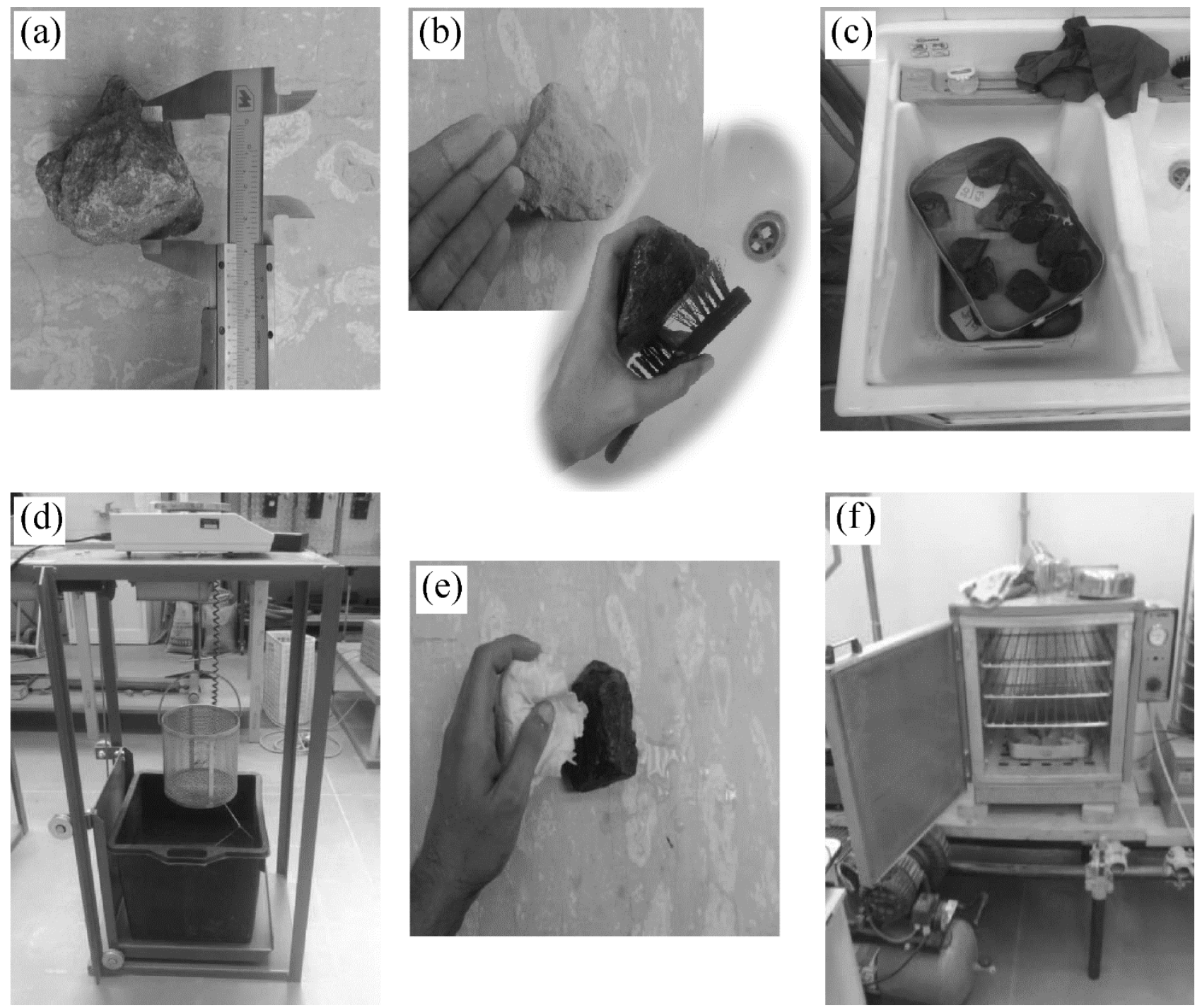

Fig. 1. Test procedure for the wire basket method [7]: (a) sampling and measurement of the aggregates by calibre; (b) cleaning and removal of fine particles within a number of aggregates retained on the $63 \mathrm{~mm}$ and the 31,5 mm test sieves; (c) water-soaking of the sampled ballast aggregates; (d) measurement of the apparent weight of the material soaked in water by a hydrostatic weighing table; (e) drying of the sampled material by absorbent paper; (f) drying of the sampled material by oven at $110 \mathrm{C}^{\circ}$ until the achievement of a constant weight of the aggregates.

In addition to the above mechanical and physical properties included in the EN 13450:2002/AC:2004 standard test method [3], the evaluation of the percentage of intergranular voids was made according to the EN 10973:1998 standard [8]. The index found was cross-checked by weighing the distilled water content which filled the inter-particle voids of a number of sampled ballast aggregates within a laboratory formwork of known volume (Fig. 2). By correlation of the weight collected for the distilled water to the water density (modified as 
a function of the room temperature), it was found a value of $39 \%$ for the voids parameter. This value agrees with the benchmark values indicated by Sussmann et al. [27] in the case of loose ballast aggregates.

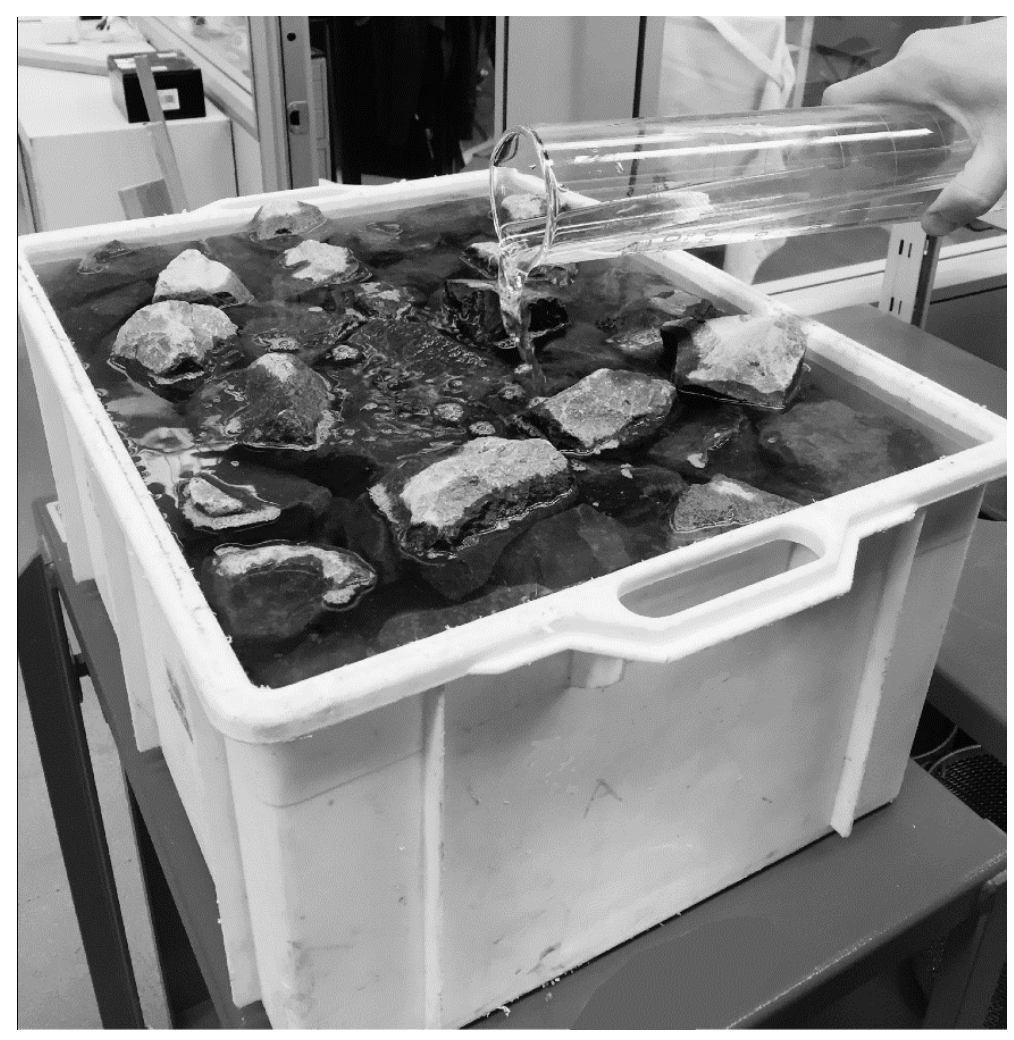

Fig. 2. Distilled water filling the inter-particle voids of ballast aggregates within a test formwork as part of the laboratory procedures for the evaluation of the percentage of voids.

Furthermore, the value of the water content parameter $w$ was determined according to the CEN ISO/TS 178921:2005 standard [9]. This standard was used for the assessment of the moisture of the ballast aggregates taken from the quarry and the evaluation of the time required for drying the materials and performing the experimental tests at controlled room conditions. The water content $w[\%]$ was calculated as follows:

$$
w=\frac{m_{1}-m_{2}}{m_{2}-m_{c}} \times 100=\frac{m_{v}}{m_{d}} \times 100
$$

where $m_{1}[\mathrm{~g}]$ is the mass of the container and the moist test specimen, $m_{2}[\mathrm{~g}]$ is the mass of the container and the dried test specimen, $m_{c}[\mathrm{~g}]$ is the mass of the container, $m_{v}[\mathrm{~g}]$ and $m_{d}[\mathrm{~g}]$ are, respectively, the water and the dried test specimen masses. Three samples were collected at three random locations within the aggregate storage available from the quarry. A reference value of $w$ equals to $0.2 \%$ was found for the ballast aggregates used in this study. 


\subsubsection{Pollutant soil material}

A fine-grained loose soil material was used for pollution of the clean ballast aggregates in order to reproduce various fouling conditions. The most important geometric (i.e., the grain size), mechanical and physical properties (i.e., plasticity, particle density, water content at room temperature) were determined in the laboratory environment (Fig. 3). The relevant values are listed in Table 2.
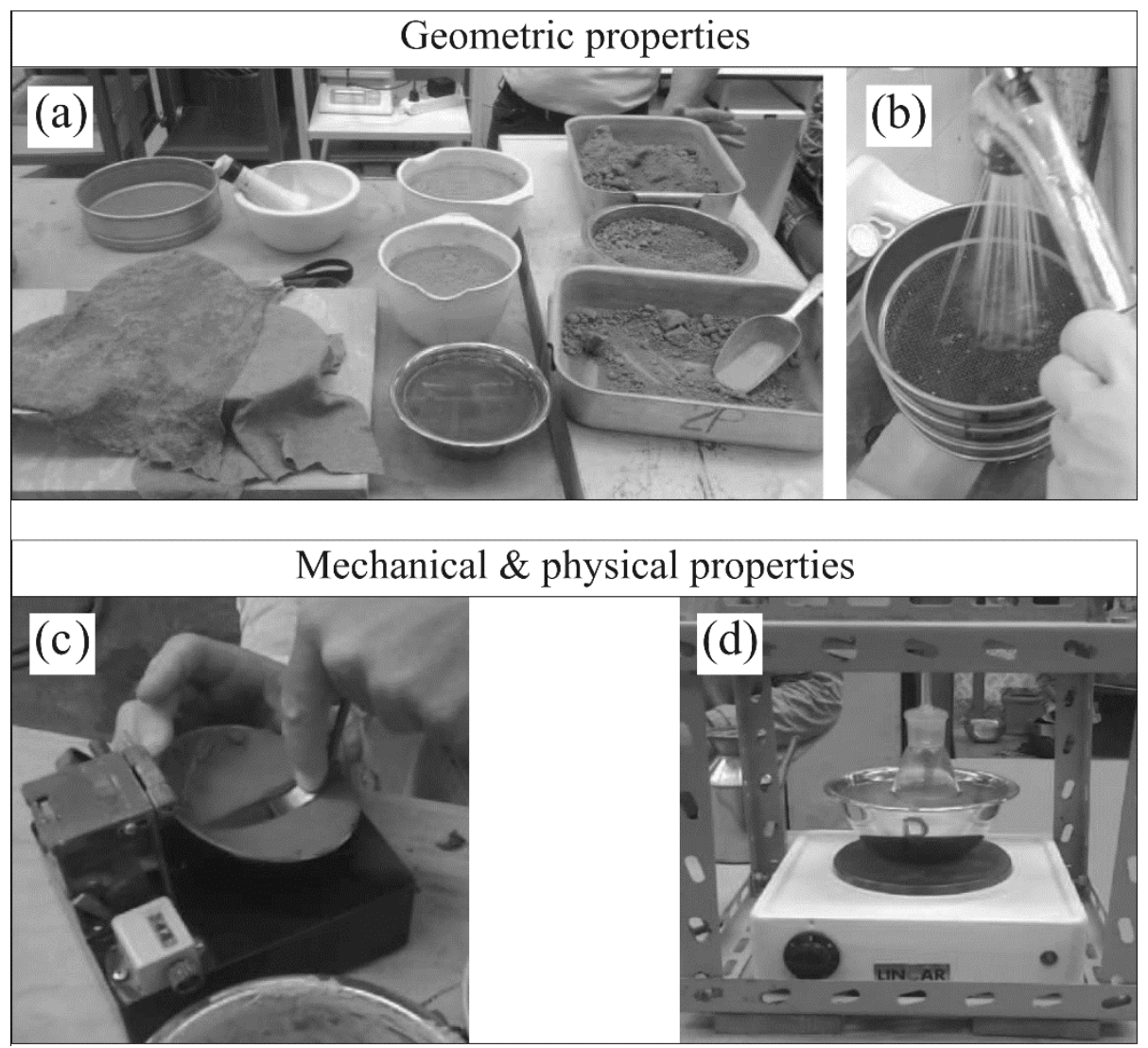

Fig. 3. Tests performed in the laboratory environment for the assessment of the pollutant soil material: (a) samples preparation; (b) soil particles sieving under water flow (grain size analysis) [4]; (c) cutting of a standard groove into the molded material with a test-specific knife (soil plasticity test) [10]; (d) boiling of the immersed specimen for deaeration (particle density evaluation test) [12].

Table 2 Geometric, mechanical and physical properties assessed in the laboratory environment for the pollutant soil material.

\begin{tabular}{|c|c|c|c|c|c|}
\hline \multicolumn{2}{|c|}{ Soil loose material property } & Regulation & Reference unit & Value & Class \\
\hline Geometric & Grain size & $\begin{array}{c}\text { EN 933-1:2012 } \\
{[4]}\end{array}$ & $\begin{array}{c}\% \text { passing vs. } \\
\text { sieve size }(\mathrm{mm}) \text { : } \\
4.75-2-0.425- \\
0.075\end{array}$ & $\begin{array}{c}100-99.6-99.4 \\
-84.7\end{array}$ & $\begin{array}{c}\text { A4 } \\
- \text { AASHTO - } \\
{[11]}\end{array}$ \\
\hline
\end{tabular}




\begin{tabular}{|c|c|c|c|c|c|}
\hline \multirow[b]{2}{*}{ Mechanical \& } & $\begin{array}{l}\text { Liquid limit } \\
-L_{L}-\end{array}$ & \multirow{2}{*}{$\begin{array}{c}\text { ASTM } \\
\text { D4318-10e1 } \\
{[10]}\end{array}$} & \multirow{2}{*}{$\%$} & 24.6 & \\
\hline & $\begin{array}{c}\text { Plastic index } \\
-I_{P}-\end{array}$ & & & 7.6 & \\
\hline \multirow[t]{2}{*}{ physical } & $\begin{array}{c}\text { Particle density } \\
-\rho_{s}-\end{array}$ & $\begin{array}{c}\text { EN ISO } 17892- \\
3: 2015 \\
{[12]} \\
\end{array}$ & $\mathrm{g} / \mathrm{cm}^{3}$ & 2.5 & / \\
\hline & $\begin{array}{l}\text { Water content } \\
\qquad-w(\theta)-\end{array}$ & $\begin{array}{c}\text { CEN ISO/TS } \\
17892-1: 2005 \\
{[9]}\end{array}$ & $\%\left(\mathrm{~cm}^{3} / \mathrm{cm}^{3}\right)$ & $2.5(4.0)$ & I \\
\hline
\end{tabular}

Grain size analyses [4] (Fig 3(a-b)) and plasticity tests [10] (Fig. 3(c)) were performed to identify the class of the material within the framework of the American Association of State Highway and Transportation Officials (AASHTO) soil classification [11]. To this purpose, the percentage of soil particles passing the $0.075 \mathrm{~mm}$ sieve size greater than $35 \%$ along with the liquid limit $L_{L}$ and the plastic index $I_{P}$ of, respectively, $24.6 \%$ and 7.6\%, allowed to classify the pollutant as a silty soil material within the A4 AASHTO group.

The particle density $\rho_{s}$ of the pollutant material is an important parameter for the investigation of the EM response of the soil $[28,29]$. Furthermore, it was also used in the literature for identifying various indexes of fouling [30, 31]. The particle density was determined according to the EN ISO 17892-3:2015 standard [12] (Fig. 3(d)) and evaluated as follows:

$$
\rho_{s}=\frac{p}{p+p_{2}-p_{1}} \cdot \rho_{w}
$$

being $p$ the dry mass of the specimen, $p_{l}$ the mass of the pycnometer, completely filled with the saturated specimen and the control liquid; $p_{2}$ the mass of the pycnometer, completely filled with the control liquid; $\rho_{w}$ the density of the control liquid (whose values are given in the norm as a function of the temperature $T$ ). The average of the results obtained from three tests has returned a value of $2.5 \mathrm{~g} / \mathrm{cm}^{3}$ for $\rho_{s}$.

The environmental water content of the silty soil $w$ was determined after oven drying all the material and leaving it at room temperature and ambient humidity for seven days. The soil moisture has been then evaluated according to the CEN ISO/TS 17892-1:2005 standard [9], and turned out to be $2.5 \%$ (i.e., $\theta=4 \mathrm{~cm}^{3} / \mathrm{cm}^{3}$ ).

\subsection{GPR equipment}

The experimental tests were performed using three air-coupled pulsed radar systems [32] all manufactured by IDS Georadar (Fig. 4), with central frequencies of 1000 MHz (RIS Hi-Pave HR1 1000), and 2000 MHz (RIS Hi-Pave HR1 2000 and 2000 NA). Time windows of 25 ns and 15 ns were set for the $1000 \mathrm{MHz}$ and the 2000 
MHz systems, respectively. With regards to the $2000 \mathrm{MHz}$ radar systems, one ordinary (i.e., $2000 \mathrm{MHz} \mathrm{EU}$ ) and one low-powered (i.e., $2000 \mathrm{MHz}$ NA) version of the horn antennas for the European (EU) and the NorthAmerican (NA) markets, respectively, were used for testing purposes. Nominal resolutions (quarter of wavelength criteria) of $7.5 \times 10^{-2} \mathrm{~m}$ and $3.75 \times 10^{-2} \mathrm{~m}$ can be reached by the $1000 \mathrm{MHz}$ and $2000 \mathrm{MHz}$ central frequency antennas, respectively. This complies satisfactorily with the aggregates particle size, roughness, voids content as well as with the fouling scenarios that will be described in the following Sections.

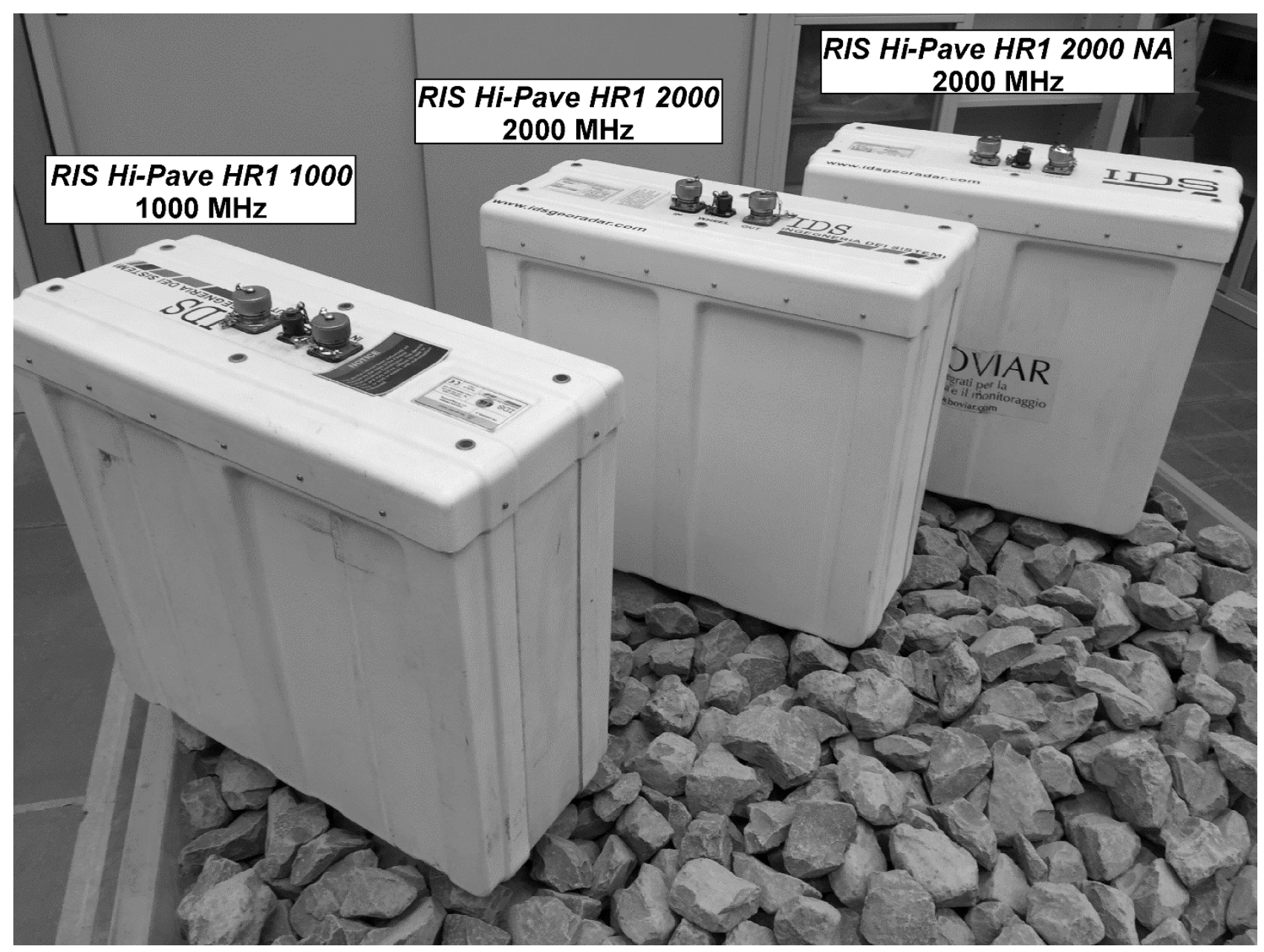

Fig. 4. Air-coupled radar systems used for the experimental surveys.

\subsection{Laboratory setup and testing}

\subsubsection{Testing equipment}

The railway ballast aggregates were investigated within a square-based methacrylate tank, with an outer base side and height of, respectively, $1.55 \mathrm{~m}$ and $0.55 \mathrm{~m}$ (Fig. 5), and inner dimensions of $1.47 \mathrm{~m}$ for both the base sides and $0.48 \mathrm{~m}$ for the height. A number of preliminary investigations were performed to determine the most 
suitable manufacturing material (i.e., methacrylate) and the dimensions of the tank, in order to i) provide data consistent with real-life scenarios and the arrangement of railway ballast aggregates; ii) reproducing effectively the action of relevant physical agents which may affect the mechanical behaviour of the railway ballast layer; iii) avoiding any edge effects which may cause noise disturbances on the EM signal; iv) allowing direct observation of both the aggregates/pollutant-soil arrangement and the evolution of the physical-mechanical occurrences inside the tank.

The height of the tank was chosen according to typical design thicknesses of the granular ballast layer. These usually range between $0.45 \mathrm{~m}$ and $0.75 \mathrm{~m}$ [33]. In addition, the average dimension and roughness of the used aggregate particles along with the reference size of the inter-particle voids were taken into account for design purposes. The width and depth of the tank were established after the evaluation of the antennas' footprints as per the information provided by the manufacturer. Further experimental tests were carried out to confirm the given data. To this purpose, analyses of the boundaries of noise effects to the signal were performed and a reference GPR standard on air-coupled radar systems [34] was followed. The tank dimensions (width and depth) also comply with the planimetric dimensions of common track beds, when considering the distance between the rails and the length of the sleepers [35].

The tank was laid above a $2 \mathrm{~m} \times 2 \mathrm{~m}$ copper-made perfect electric conductor (PEC) sheet, which allowed to reflect completely the waves propagating through the investigated material [36]. Indeed, the use of a PEC avoids the propagation of the EM wave through the floor and prevents to illuminate possible sources of noise such as the structural concrete or the reinforcement bars embedded in the ground of the laboratory. Calibration measurements complying with the ASTM D6087-08 standard [34] were performed and a reference distance of $0.40 \mathrm{~m}$ between the bottom of each GPR apparatus and the PEC was set. 


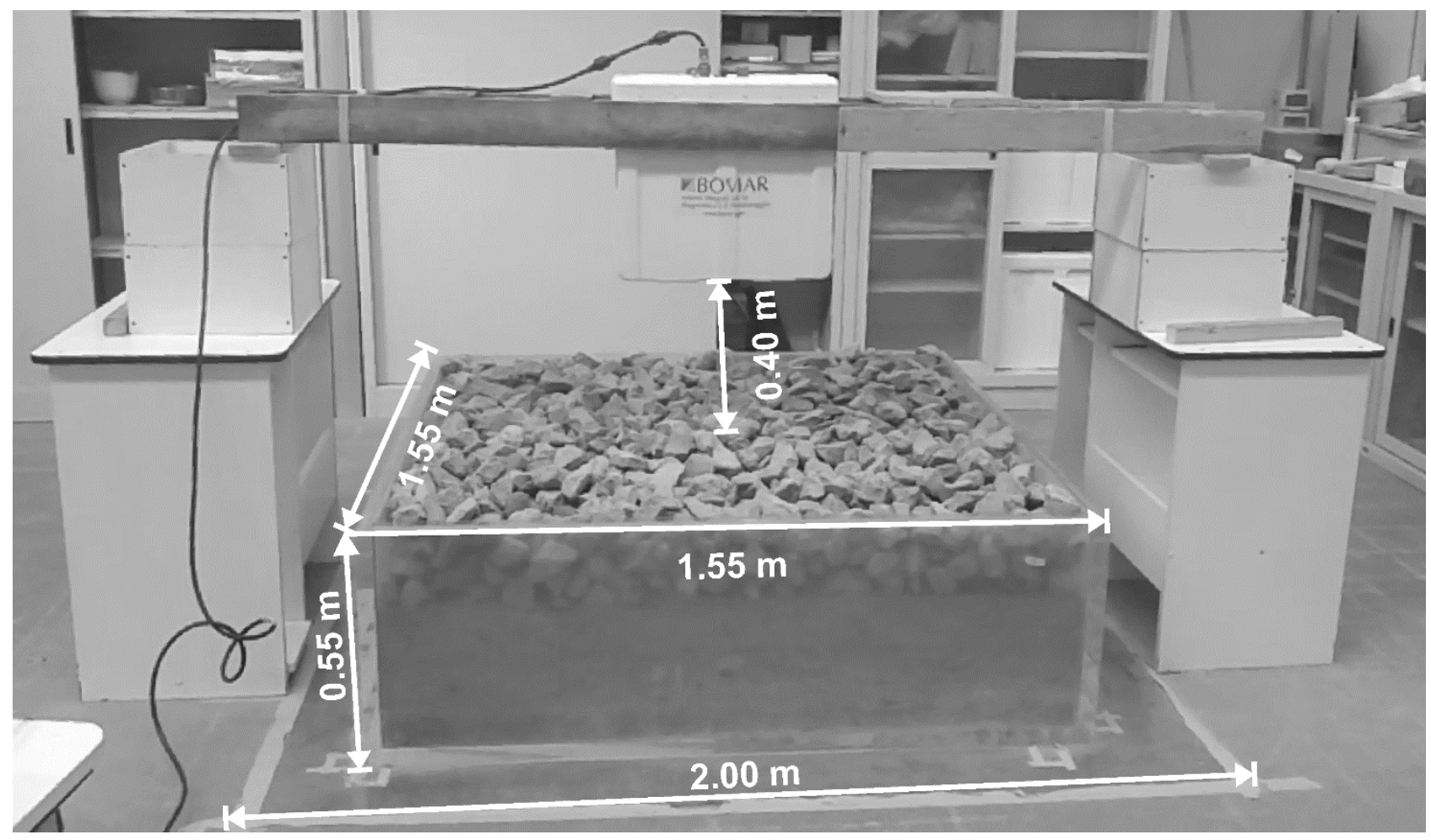

Fig. 5. Laboratory setup used for the GPR tests.

\subsubsection{Procedures for materials layout}

The considerable size of the investigation domain and the relevant amount of ballast aggregates $(\sim 1500 \mathrm{~kg})$ and pollutant soil material (from $\sim 250 \mathrm{~kg}$ to $\sim 800 \mathrm{~kg}$, depending on the fouling level) to manage, have led to developing small-scale laboratory procedures. These have favoured standardizing the mechanical and physical conditions reproduced for the material within the volume of the tank.

To ensure the effective distribution and uniformity of the pollutant material within the ballast inter-particle voids, a wooden square grid mesh of 16 quadrants with $0.35 \mathrm{~m}$ sides (Fig. 6(a)) was equipped with a $4 \mathrm{~mm}$-size sieving grid (Fig. 6(b)). 


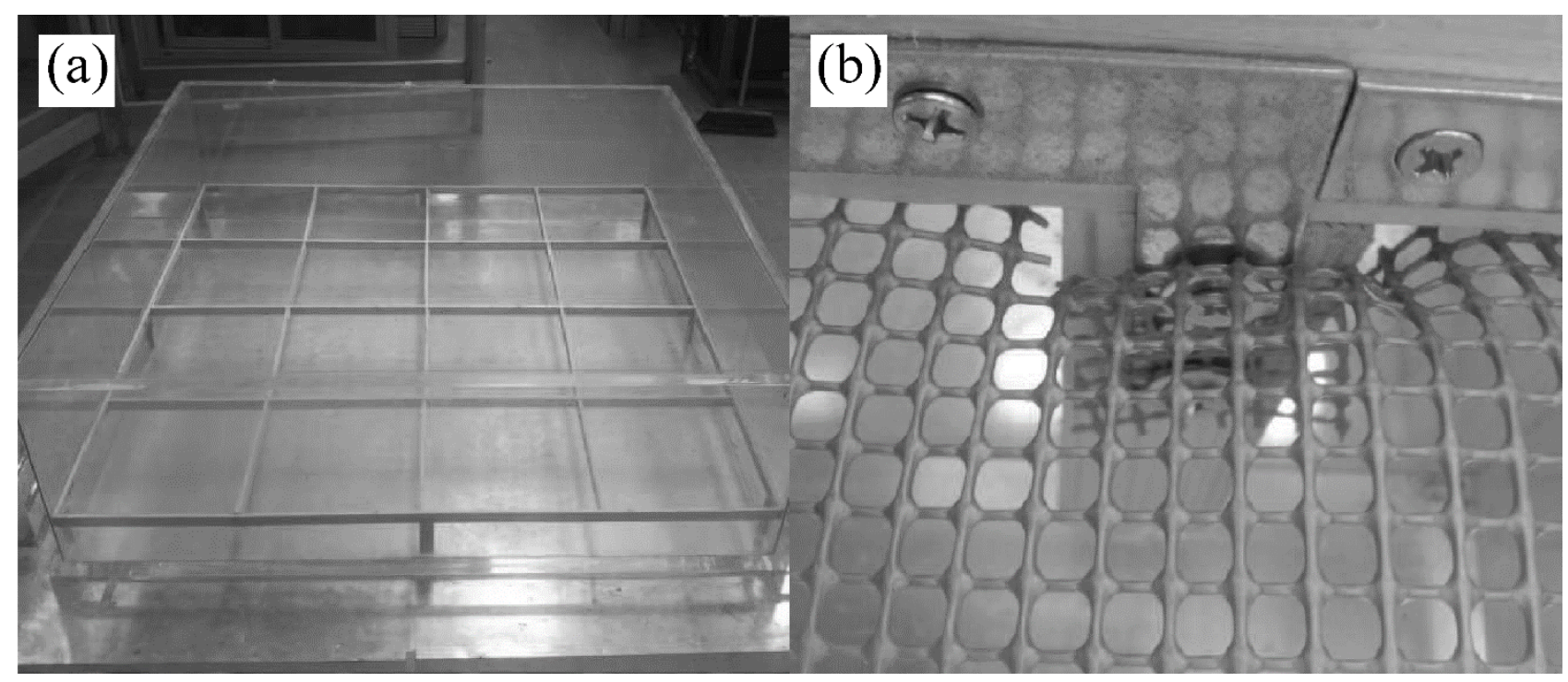

Fig. 6. Equipment for ensuring the effective distribution of the pollutant material within the railway ballast inter-particle voids: (a) wooden square grid mesh of 16 quadrants with $0.35 \mathrm{~m}$ sides; (b) $4 \mathrm{~mm}$-size sieving grid.

Once the silty soil was distributed within the wooden support quadrants, compaction and filling of voids were obtained by using a hammer drill equipped with a square-shaped drill bit (Fig. 7(a)). To this purpose, a dedicated laboratory procedure was preliminarily implemented in a small-scale formwork with dimensions comparable to those of the above quadrants (Figs.7(b-f)). In addition, the time required for reaching the maximum compaction of the silty material with the hammer drill was evaluated. In this regard, the maximum value of dry density $\rho_{d}$ was reached after $10 \mathrm{~s}$ of vibration induced by the hammer. 

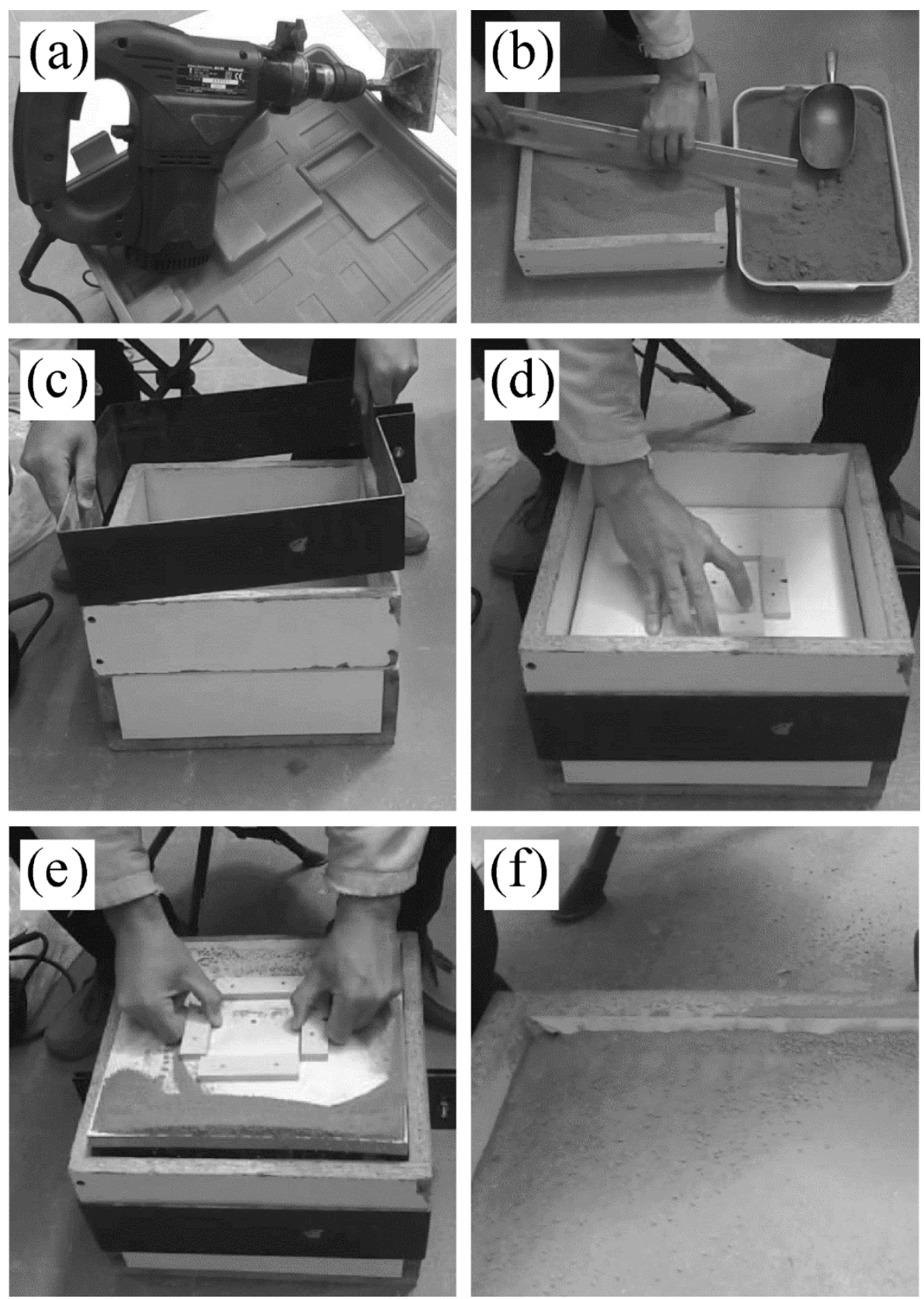

Fig. 7. Compaction procedures carried out on a small-scale formwork: (a) hammer drill equipped with a square-shaped drill bit; (b) placement and levelling of the dry silty soil material within the test formwork; (c) addition of the extension collar and connection to the formwork by means of a metal connector to prevent material waste during compaction; (d) induction of 10s steps of vibration by resting the square-shaped drill bit to the formwork cover cap; (e) removal of the cover cap and (f) measurement of the induced subsidence.

To make the results from the proposed compaction procedure comparable to the outcomes of relevant standard test methods, the energy of compaction spent with the hammer drill has been compared to the same parameter achieved with i) the Proctor test for mixes compacted with a $2.5 \mathrm{~kg}$ rammer in the Proctor mould and ii) the 
Modified Proctor test for mixes compacted with a $4.5 \mathrm{~kg}$ rammer in the large Proctor mould [37]. The overall compaction energy per unit volume spent with the hammer amounts to $1.04 \times 10^{6} \mathrm{~J} / \mathrm{m}^{3}$, whereas values of $0.59 \times 10^{6} \mathrm{~J} / \mathrm{m}^{3}$ and $2.68 \times 10^{6} \mathrm{~J} / \mathrm{m}^{3}$ were found for the Proctor and the Modified Proctor tests, respectively. In view of the obtained values of energy, it can be therefore argued how the compaction procedure here proposed ranks between the Standard and the Modified Proctor test.

\subsubsection{Test scenarios}

Four main configurations (Table 3) were manufactured in the laboratory environment. In all of these scenarios, the material investigated filled the entire inner tank height $h$ of $0.48 \mathrm{~m}$.

Table 3 Configurations of ballast-pollutant mixes investigated in the laboratory.

\begin{tabular}{ccc}
\hline Test scenario & $\begin{array}{c}\text { Height of the ballast-pollutant } \\
\text { mix } \\
{[\mathbf{m}]}\end{array}$ & $\begin{array}{c}\text { Configuration } \\
{[\mathbf{m}]}\end{array}$ \\
\hline & 0.48 & $0.48 \mathrm{~m}$ Clean Ballast (CB) [no Fouled Ballast \\
& & $(\mathrm{FB})]$ \\
I & 0.48 & $0.10 \mathrm{~m} \mathrm{FB}+0.38 \mathrm{~m} \mathrm{CB}$ \\
II & 0.48 & $0.20 \mathrm{~m} \mathrm{FB}+0.28 \mathrm{~m} \mathrm{CB}$ \\
III & 0.48 & $0.30 \mathrm{~m} \mathrm{FB}+0.18 \mathrm{~m} \mathrm{CB}$ \\
\hline
\end{tabular}

Starting from clean ballast conditions (i.e., Test scenario 0), the fouling was reproduced by layers of a mix between the pollutant A4 silty soil and the ballast aggregates. The height of this mix was progressively increased by steps of $0.10 \mathrm{~m}$. Mixing and compaction of the materials were performed according to the procedures discussed in Section 4.4.2. The above-fouled configurations were set to be representative of low (i.e., $0.10 \mathrm{~m}$ of fouled ballast (FB) - Test scenario I), medium (i.e., $0.20 \mathrm{~m}$ of FB- Test scenario II) and high (i.e., $0.30 \mathrm{~m}$ of FB- Test scenario III) levels of fouling within the ballast layer of a railway track bed.

A loop laboratory procedure was followed for manufacturing the four scenarios. Starting from no-fouled ballast conditions (i.e., Test scenario 0), the clean ballast aggregates have been removed from the top of the tank at progressively lower amounts each more step, up to reaching the wanted height of the fouled layer. Therefore, 
mixing and compaction procedures were carried out. Afterwards, the clean ballast aggregates was placed again above the compacted fouled layer of ballast up to filling the entire height of the tank. The above "emptying and filling" loop was repeated until the conditions of scenario III were reached. The GPR surveys with the three aforementioned air-coupled antenna systems were performed at each scenario.

Fig. 8 shows the tank filled with clean ballast (Fig. 8(a)) and an all-in-one image of the above four configurations merged together (Fig. 8b)).
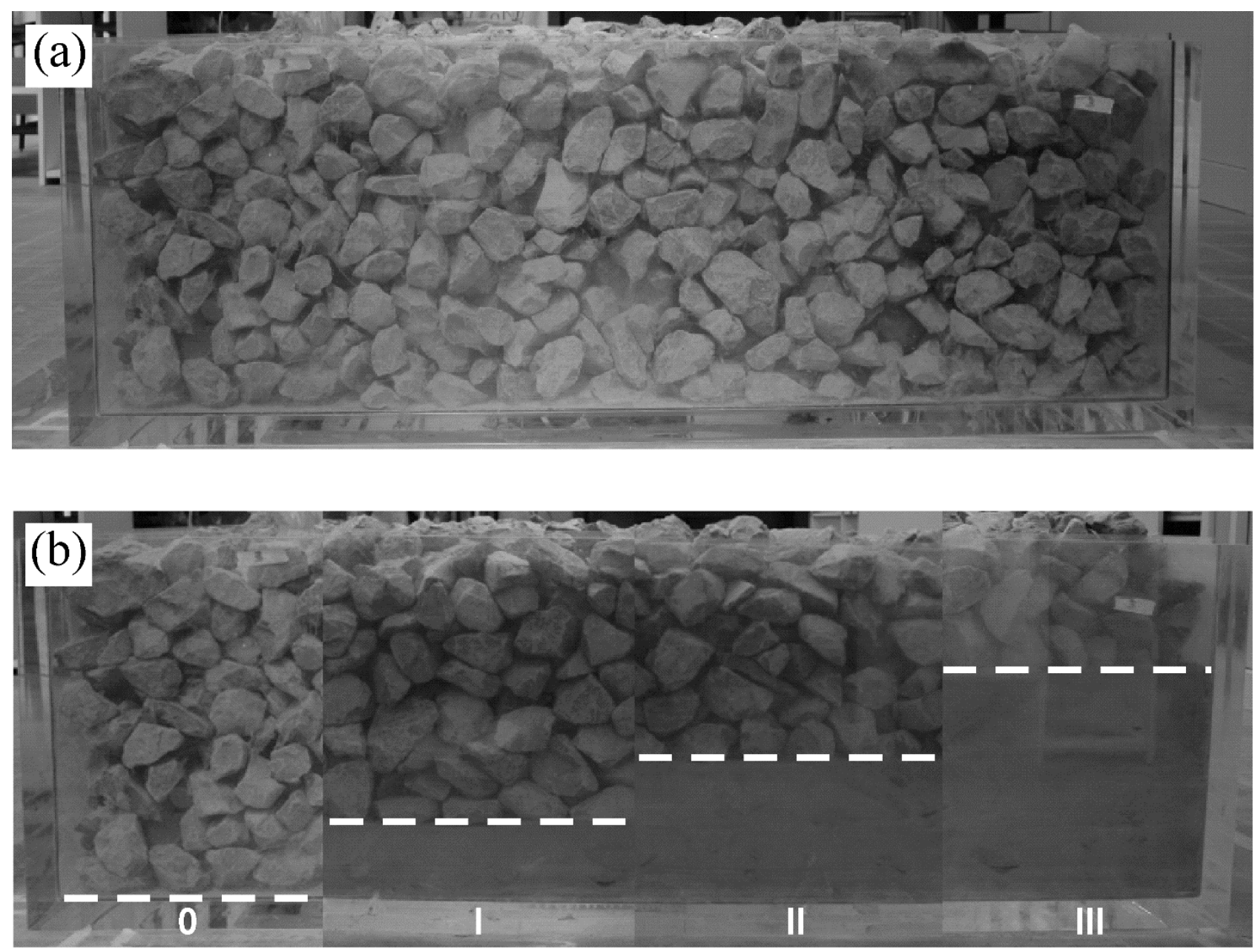

Fig. 8. (a) Methacrylate tank filled with clean ballast aggregates; (b) all-in-one image of the four scenarios merged together (the dashed lines separate the clean (top) from the uniformly-fouled (bottom) ballast layer).

\section{RESULTS}

\subsection{Relative dielectric permittivity estimate by signal processing methods}


In order to minimize the stochastic variability of the signals, a number of 100 traces were collected at each reproduced scenario and the average trace was taken. In view of this, one unique (average) A-scan was related to each tested configuration. The average traces representative of the four investigated scenarios are depicted in Fig. 9. Thereby, the value of the relative dielectric permittivity $\varepsilon_{r}$ of the ballast/air/pollutant mix was inferred from each of these traces using differing processing techniques.

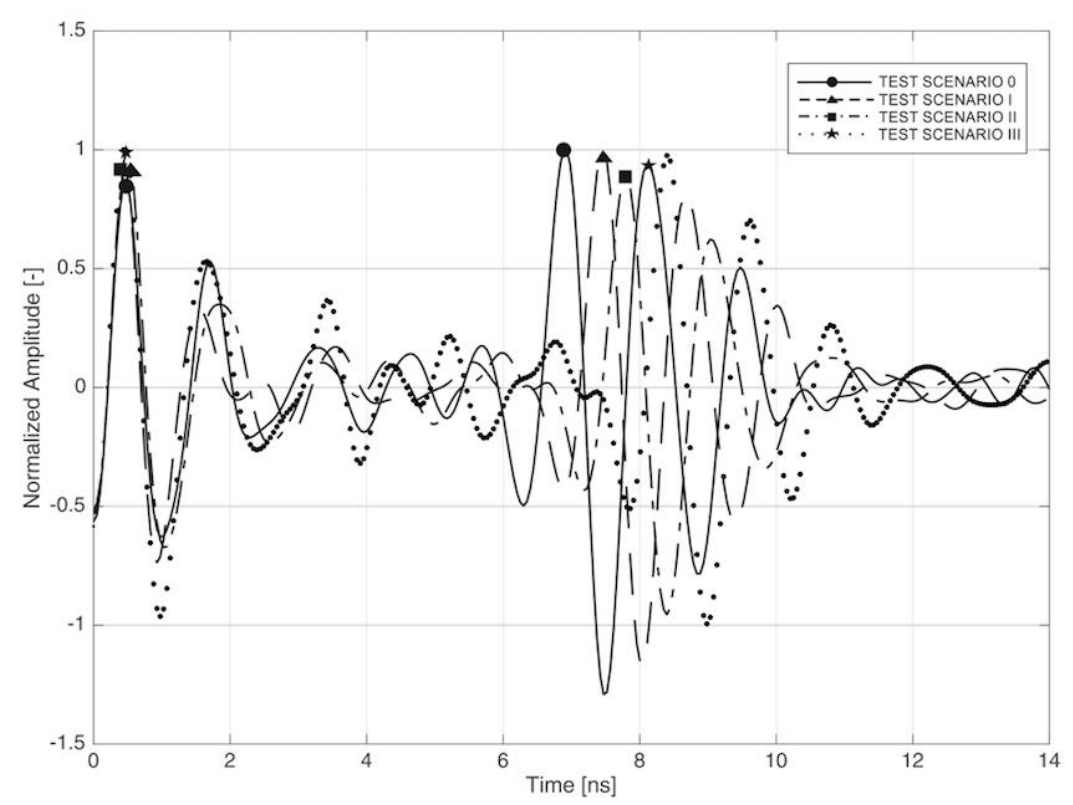

Fig. 9. Average traces obtained for the four tested scenarios. Line styles indicate the different scenarios, whereas the markers point out the position of the reflection peaks at the interfaces between the air-ballast and the ballast-metal plate.

The time-domain signal picking (TDSP) technique [38] accounts for the time interval between the reflection peaks of the first (air/ballast) and the last interface (ballast/PEC), i.e., the two-way travel time $t$ taken by the EM wave for propagating through the material. Since the thickness $h$ of the tank is known, it is possible to infer the propagation speed $v=2 h / t$, hence, the relative dielectric permittivity as follows:

$$
\varepsilon_{r}=\left(\frac{c_{0}}{v}\right)^{2}
$$

with $c_{0}$ being the speed of light. 
The surface reflection method (SRM) [39] is based on the comparison between the amplitude $A_{0}$ of the reflection peak from the air/surface interface, and the reference amplitude $A_{P E C}$ reflected by a metal plate (perfect electric conductor (PEC)) larger than the GPR footprint. The relevant relationship is expressed as follows:

$$
\varepsilon_{r}=\left(\frac{\left(1+\frac{A_{0}}{A_{P E C}}\right)}{\left(1-\frac{A_{0}}{A_{P E C}}\right)}\right)^{2}
$$

In order to reach the maximum accuracy in the estimation of the permittivity, both the amplitudes must be recorded at the same height from the reflector. In this regard, it is worth to emphasize on the difficulty to reach a stable value for the height during the operations. This is due to the size and the rough shape of the ballast aggregates which cannot provide a smooth reflection interface.

\subsection{Relative dielectric permittivity estimate by theoretical models}

The volumetric mixing formula (VMF) approach [40] was performed to compute the dielectrics using a theoretical multi-phase modelling of the scenarios investigated. This method requires the knowledge of both the relative dielectric permittivity $\varepsilon_{r, i}$ and the corresponding volumetric fraction $f_{i}$ of each $i^{\text {th }}$ component of the mix. These parameters are arranged in the linear combination given by Eq (8):

$$
\varepsilon_{r}^{\alpha}=\sum_{i} f_{i} \varepsilon_{i}^{\alpha}
$$

with $\alpha$ being a geometric fitting parameter, whose values were investigated in the literature [41-44]. In this study, a value of 0.5 was used for the $\alpha$ factor. Table 4 lists the parameters set in Eq. (8).

\begin{tabular}{|c|c|c|c|c|c|}
\hline $\mathrm{i}^{\text {th }}$ Component & $\varepsilon r, i$ & $\left.f_{i}{ }^{(\mathrm{FL} \mathrm{0}}\right)^{*}$ & $f_{i}^{(\mathbf{F L} \mathbf{I})}$ & $f_{i}^{(\text {FL II })}$ & $f_{i}^{(\text {FL III) }}$ \\
\hline Ballast & 6.50 & 0.53 & 0.53 & 0.53 & 0.53 \\
\hline A4 Soil & 5.03 & 0.00 & 0.08 & 0.16 & 0.24 \\
\hline Methacrylate & 4.00 & 0.08 & 0.08 & 0.08 & 0.08 \\
\hline
\end{tabular}

Table 4 Values of the parameters set in Eq. (8). 


\begin{tabular}{cccccc} 
Air & 1.00 & 0.39 & 0.31 & 0.22 & 0.14 \\
\hline *FL - Fouling Level & & & & & \\
\hline
\end{tabular}

The values of the dielectric permittivity of the ballast (i.e., the dielectrics of the source limestone-derived rock) and the methacrylate were derived from the literature [45]. The dielectric permittivity of the A4 silty soil was assessed by the application of the TDSP technique on the GPR data collected within a $0.10 \mathrm{~m}$ height layer of this material (laid out within the (same) empty methacrylate tank).

\subsection{Methods comparison}

Comparisons between the outcomes of each of the two signal processing-based methods and the VMF are given in Fig. 10. The results obtained from the full set of used antenna frequencies are depicted.

With regard to the permittivity estimates by the TDSP technique (Fig. 10(a)), it is worth noting the overall good agreement between the dielectrics achieved in all the case-scenarios across the full set of used frequencies. Values of permittivity comprised between 3.51 and 5.35 , which raise consistently with the increasing levels of fouling, were observed. This behaviour accords with the theoretical assumptions of increasing rates of air voids $\left(\varepsilon_{r, a}=1\right)$ that get progressively filled with the pollutant material, which is characterized by a higher permittivity value (i.e., $\varepsilon_{r}=5.03$ ). Thereby, the relative dielectric permittivity of the whole multi-phase system tends to increase. These results and the overall trend of permittivity values versus the level of fouling are well confirmed by the volumetric approach. The modulus of the incidences of the residuals (i.e., the percentage ratio of the difference between the VMF and the TDSP permittivity values (numerator), and the corresponding dielectrics by the VMF (denominator)) is comprised between $0.10 \%$ and $6.90 \%$. In addition and with respect to the trend of the estimates obtained across the four investigated scenarios, the permittivity values retrieved with the TDSP are overall lower than the corresponding VMF values. Exceptions are the estimates reached with both the $2000 \mathrm{MHz}$ systems in clean conditions (i.e., scenario 0) and the permittivity retrieved with the $1000 \mathrm{MHz}$ GPR in highly-fouled conditions (i.e., scenario III). 

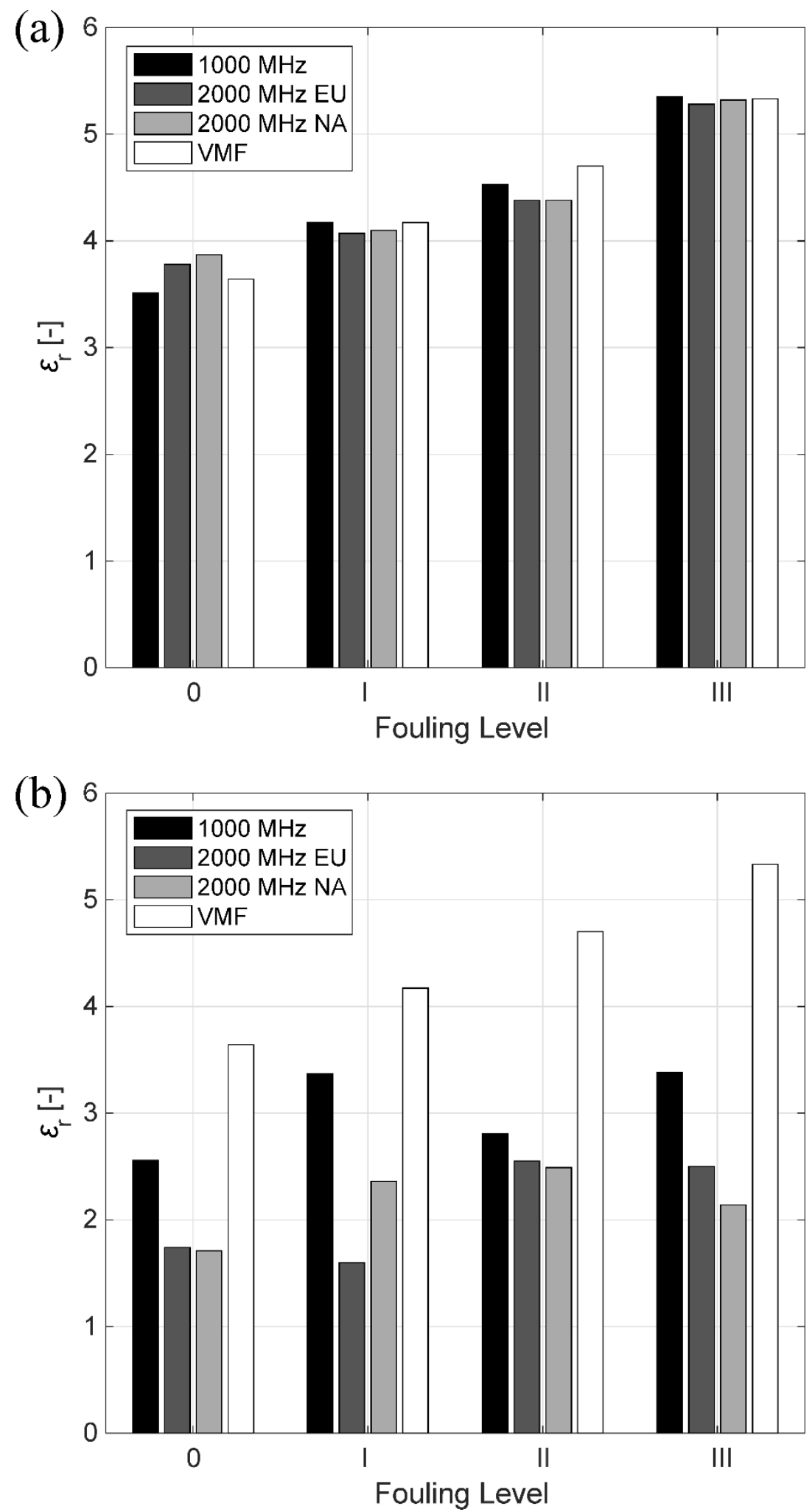

Fig. 10. Relative dielectric permittivity estimates for the acquisitions made with the $1000 \mathrm{MHz}, 2000 \mathrm{MHz}$ EU, and $2000 \mathrm{MHz}$ NA antenna systems using the TDSP and the VMF (a), and the SRM and the VMF (b).

On the contrary, the outcomes from the application of the SRM are not consistent with the VMF estimates such as in the case of the TDSP technique. From Fig. 10(b), it is clear how the SRM approach returned lower 
values of permittivity with respect to both the VMF and the TDSP techniques and proved to be not suitable to assess both the clean and the fouled ballast condition across all the investigated scenarios. A possible motivation for this mismatching falls within the amplitude-based nature of the own method and the coarse grain size and rough shape of the ballast aggregates. Indeed, the SRM relies on the value of the first-peak amplitude of the collected signal, which in turn depends on several factors including the configuration of the air-surface interface. In this regard, it is worth mentioning that the surface configuration of the four scenarios (i.e., the arrangement of the clean ballast aggregates at the top of the tank) has changed in all the investigated cases, due to the requirements of the testing protocol for laying out the material (i.e., Section 4.4.3). In addition, it is well-known how the wavelength of the signal is a critical survey parameter in the case of railway ballast, due to the variability of the dimension and shape of the aggregates, as well as of the volume of the air-filled voids (which can vary according to the fouling level). The consistency between the wavelength of a GPR signal and the dimension of the targets in a railway track bed (e.g., the ballast aggregates or the air voids) generates considerable scattering patterns and affects, amongst the other, the first-peak amplitude of the signal. As a rule of thumb, the lower is the frequency of investigation, the longer is the signal wavelength, the smaller will be the scattering generated by the ballast aggregates and the air voids. In such a case, the energy extracted to the signal will be lower $[24,46]$. According to the wavelengths of the two central frequencies used in this study, it can be seen how the highest permittivity values closer to the above VMF (and TDSP) permittivity estimates (which are both expected to well approximate the searched dielectrics), were reached by the $1000 \mathrm{MHz}$ GPR system (Fig. 10(b)). Indeed, this is due to the longer wavelength and the lower sensitivity of this antenna frequency towards the rough shape of the surface aggregates and the dimensions of the air voids. This fact generates less scattering and lower impact on the first-peak amplitude of the signal. Thereby, permittivity estimates much closer to the expected ones were reached.

\subsection{Validation through the numerical simulation}

A new simulation-based methodology was introduced for generation of the synthetic GPR response from the investigated experimental scenarios and the validation of the results discussed in Section 5.3.

A combined approach that uses the random-sequential adsorption (RSA) algorithm [47] and the finitedifference time-domain (FDTD) technique [48-50] was implemented for the simulation of the GPR signal. The 
RSA paradigm was first used for generating random bi-dimensional (2-D) distributions of the compacted ballast aggregates, which were schematically represented by a comprehensive set of circumferences with different diameters. The RSA algorithm follows two main steps. As a first mandatory selection condition, the grain size distribution of the circumferences needs to comply with the experimental (actual) one (i.e. Table 1). As a result, the algorithm returned an amount of 200 circumferences, on the average, with diameters ranging from $2.5 \cdot 10^{-2} \mathrm{~m}$ and $8 \cdot 10^{-2} \mathrm{~m}$. The second step of the RSA algorithm allows compacting the circumferences along the vertical axis for ensuring the contacts between the aggregates and reaching a content of voids equal to $39 \%$. This value was constrained to the one obtained from the standard test methods in the laboratory.

Afterwards, the generated 2-D scenario was simulated using the FDTD technique implemented in the gprMax 2D simulator [51]. The physical structure of the GPR antenna was not included in the model. The real test environment was reproduced by positioning a source of a line of current in the free space at a height from the target equals to the actual height of the antenna source. The exact test domain was accurately designed with respect to the size of the tank, the layers composing the investigated multi-phase system (ballast/methacrylate/PEC) and the dielectric properties of the materials involved (Fig. 11). Detailed information about the simulation can be found in Benedetto et al. [52].

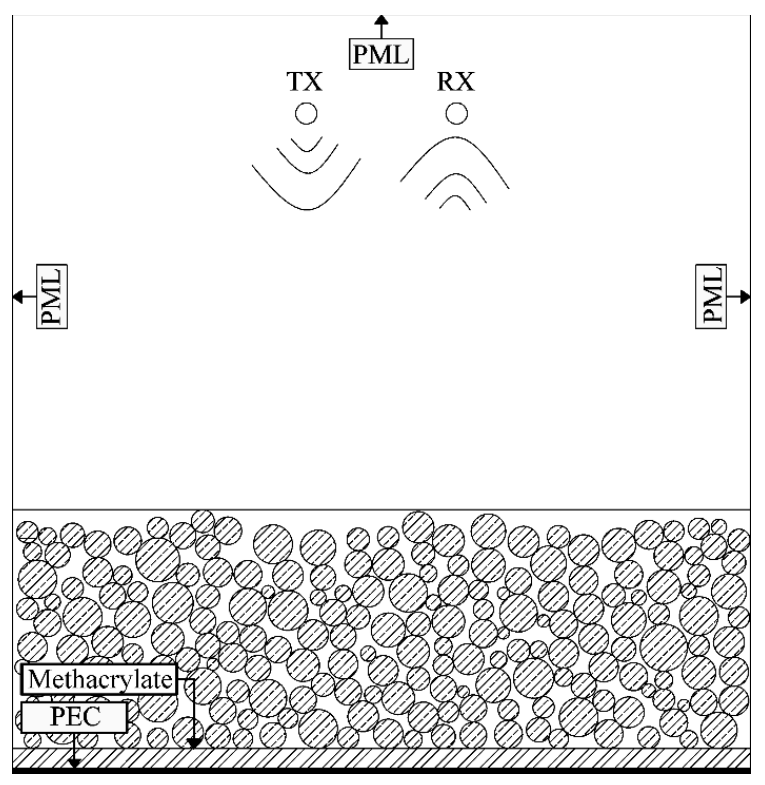

Fig. 11. The simulation domain.

At the current stage of the research, the GPR signals obtained over the full set of scenarios using the 1000 MHz central frequency were simulated. In Fig 12 the comparison between the measured and the simulated 
signals is shown for each combination of ballast and pollutant material. The overall good matching between the radar sweeps indicates a good reliability of the used simulation-based approach. In addition, the relatively good agreement between the measured and simulated signals (in terms of time distance between the first (i.e., air-ballast interface) and the last (i.e., ballast-PEC interface) peak) allows to validate the values of the relative dielectric permittivity computed for the whole set of the scenarios using the TDSP technique (i.e., Fig. 10(a)).
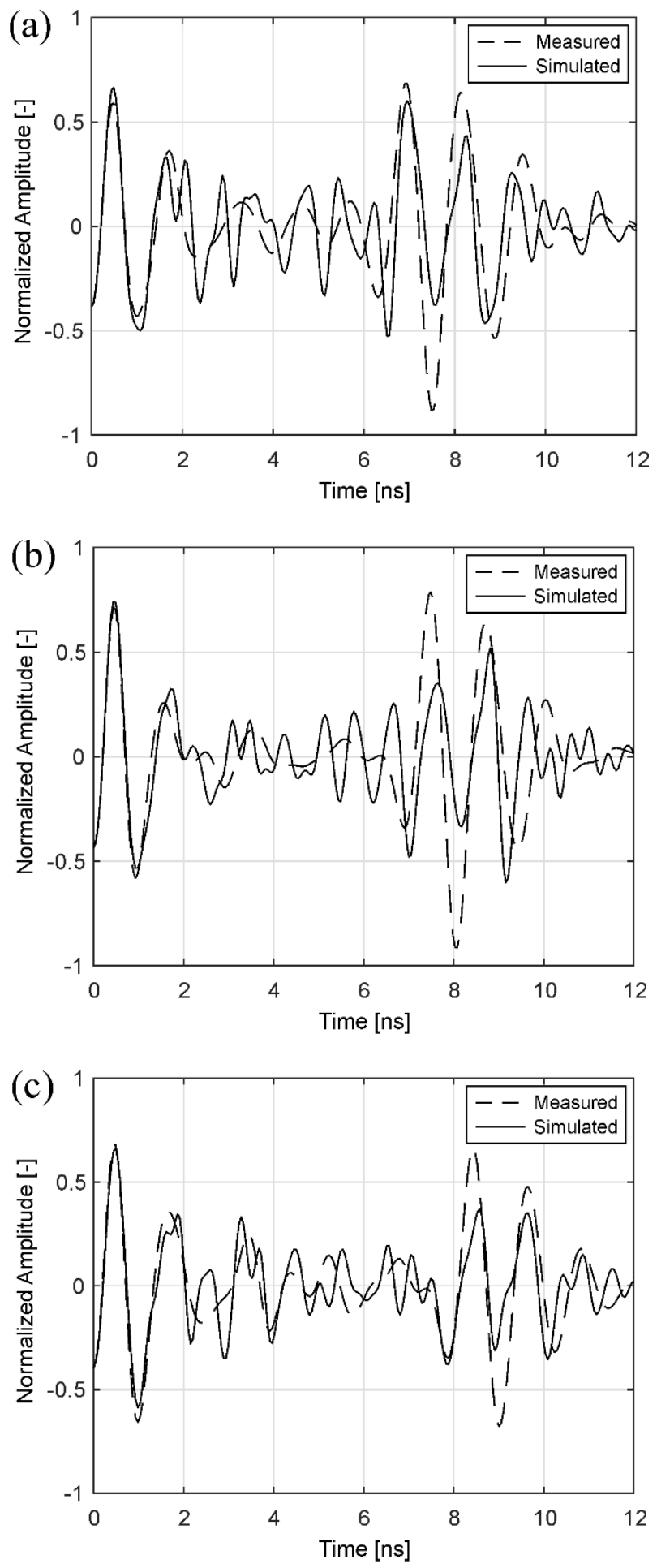


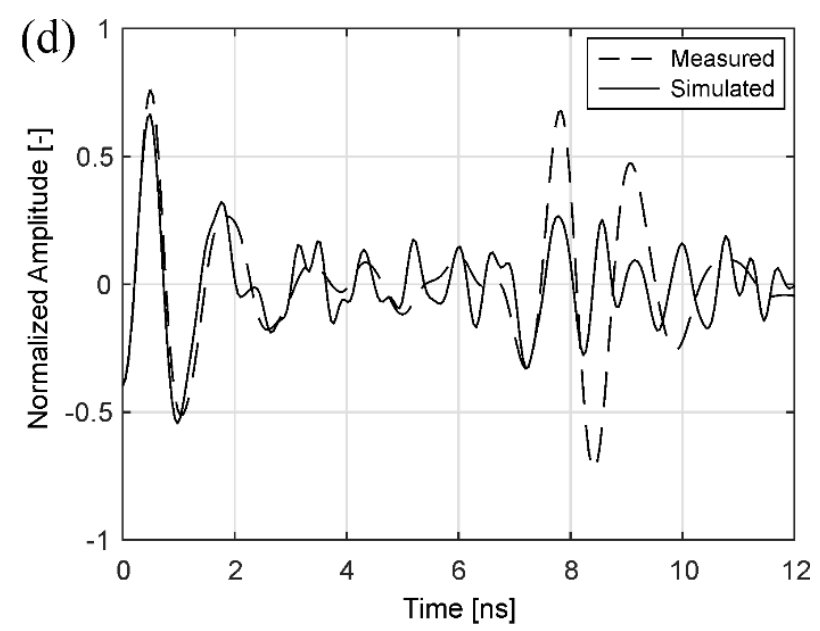

Fig. 12. Comparison between measured (dashed line) and simulated data (solid line) for the investigated scenarios: $0.48 \mathrm{~m}$ of clean ballast -Scenario 0 - (a); $0.10 \mathrm{~m}$ of fouled ballast beneath $0.38 \mathrm{~m}$ of clean ballast Scenario I - (b); $0.20 \mathrm{~m}$ of fouled ballast beneath $0.28 \mathrm{~m}$ of clean ballast-Scenario II - (c), $0.30 \mathrm{~m}$ of fouled ballast beneath $0.18 \mathrm{~m}$ of clean ballast - Scenario III - (d).

\section{CONCLUSION AND FUTURE PERSPECTIVES}

This work reports on the GPR-based assessment of railway ballast which was progressively "polluted" with a fine-grained silty soil material. The experimental setup was designed to represent a real-life scenario of a railway track bed. To this purpose, a methacrylate square-based tank sized $1.47 \mathrm{~m} \times 1.47 \mathrm{~m} \times 0.48 \mathrm{~m}$ height was manufactured and filled with clean ballast aggregates. The air-filled inter-particle voids were progressively "polluted" with a fine-grained silty soil, classified as A4 according to the AASHTO soil classification. Four levels of fouling within the ballast aggregate particles were reproduced. The GPR tests were performed at each fouling step using pulsed GPR systems equipped with differing air-coupled antennas of $1000 \mathrm{MHz}$ and 2000 $\mathrm{MHz}$ central frequencies. The relative dielectric permittivity values of the ballast-silty soil mixes were retrieved using two signal-processing-based methods, i.e., the time-domain signal picking (TDSP) technique and the surface reflection method (SRM), and one theoretical-based model, i.e., the volumetric mixing formula (VMF). The results showed that the values of the dielectric permittivity increased with the level of fouling and were comprised between 3.51 and 5.35. The comparison between the three models proved that the SRM turned out to be not suitable for characterizing the permittivity of the materials under investigation across the range of the used antenna frequencies. Moreover, the results emerged from the peak-to-peak estimates of the relative 
dielectric permittivity by the TDSP technique were further confirmed by the numerical-based simulation method implemented by the combination of the random-sequential (RSA) paradigm and the finite-difference time-domain (FDTD) technique. Indeed, the time position of the two main peaks of reflection (i.e., the peaks relative to the reflections from the air/ballast and the ballast/PEC interfaces) matched relatively well in both the simulated and the measured data.

It is important to emphasize on the significance of the RSA paradigm coupled with the FDTD technique used for the data processing. This was proved to be crucial and effective for the simulation of the GPR signal as well as in generating synthetic GPR responses close to the experimental data. The relatively good agreement between the measured and the simulated GPR data paves the way for future research at investigating more complex multi-phase configurations of ballast/air/fouling components.

\section{ACKNOWLEDGEMENTS}

The authors express their thanks to Mr. Spartaco Cera, from Roma Tre University, for the technical assistance and the invaluable help provided during the laboratory surveys. Special thanks to IDS Georadar for supplying part of the GPR antenna systems and Clax Italia s.r.l. for manufacturing the methacrylate tank. This work has also benefited from the network activities carried out within the EU funded COST Action TU1208 "Civil Engineering Applications of Ground Penetrating Radar.”

\section{REFERENCES}

1. M.R. Clark, R. Gillespie, T. Kemp, D.M. McCann, M.C. Forde, Electromagnetic properties of railway ballast, NDT \& E Int. 34 (2001) 305-311.

2. E.T. Selig, B.I. Collingwood, S.W. Field, "Causes of fouling in track”, AREA Bulletin, 71, 1998

3. EN 13450:2002/AC:2004. Aggregates for railway ballast. European Committee for Standardization, 2004.

4. EN 933-1:2012. Tests for geometrical properties of aggregates - Part 1: Determination of particle size distribution Sieving method. European Committee for Standardization, 2012.

5. EN 933-4:2008. Tests for geometrical properties of aggregates - Part 4: Determination of particle shape - Shape index. European Committee for Standardization, 2008. 
6. EN 1097-2:2010. Tests for mechanical and physical properties of aggregates - Part 2: Methods for the determination of resistance to fragmentation. European Committee for Standardization, 2010.

7. EN 1097-6:2013. Tests for mechanical and physical properties of aggregates - Part 6: Determination of particle density and water absorption. European Committee for Standardization, 2013.

8. EN 1097-3:1998. Tests for mechanical and physical properties of aggregates - Part 3: Determination of loose bulk density and voids. European Committee for Standardization, 1998.

9. CEN ISO/TS 17892-1:2014. Geotechnical investigation and testing - Laboratory testing of soil - Part 1: Determination of water content (ISO 17892-1:2014). European Committee for Standardization, 2014.

10. ASTM D4318-10e1. Standard Test Methods for Liquid Limit, Plastic Limit, and Plasticity Index of Soils, ASTM International, West Conshohocken, PA, 2010.

11. American Association of State Highway and Transportation Officials (AASHTO) 2011. Roadside Design Guide, 4th edn. AASHTO, Washington, DC.

12. EN ISO 17892-3:2015. Geotechnical investigation and testing - Laboratory testing of soil - Part 3: Determination of particle density (ISO 17892-3:2015, Corrected version 2015-12-15). European Committee for Standardization, 2015.

13. A. Benedetto, L. Pajewski, Civil Engineering Applications of Ground Penetrating Radar, Springer Transactions in Civil and Environmental Engineering Book Series, 2015.

14. D. Goodman, Ground-penetrating radar simulation in engineering and archaeology, Geophysics, 59 (2) (1994) $224-$ 232.

15. F. Tosti, L. Pajewski, Applications of radar systems in Planetary Sciences: an overview, Chapt. 15 - Civil Engineering Applications of Ground Penetrating Radar, Springer Transactions in Civil and Environmental Engineering Book Series, pp. 361-371, 2015.4-232, 1994.

16. J.J. Schultz, M.E. Collins A.B. Falsetti, Sequential monitoring of burials containing large pig cadavers using groundpenetrating radar, J. Forensic Sci. 51 (3) (2006) 607-616.

17. R. Roberts, A. Schutz, I.L. Al-Qadi, E. Tutumluer, Characterizing railroad ballast using GPR: recent experiences in the United States, in Proc. of the $20074^{\text {th }}$ International Workshop on Advanced Ground Penetrating Radar (IWAGPR 2007), Naples, Italy, Jun. 2007.

18. Railway Track and Structures Magazine, June 1985.

19. J. Hugenschmidt, Railway track inspection using GPR, Journal Appl. Geophys., 43 (2-4) (2000) 147-155.

20. G.R. Olhoeft, E.T. Selig, Ground penetrating radar evaluation of railroad track substructure conditions, in Proc. 9th International Conference on Ground Penetrating Radar (GPR 2002), Santa Barbara, USA, Apr. - May 2002. 
21. Z. Leng, I.L. Al-Qadi, Railroad ballast evaluation using ground-penetrating radar, Transp. Res. Rec. 2159 (2010) 110-117.

22. F. De Chiara, Improvement of railway track diagnosis using Ground Penetrating Radar, PhD Thesis, 2014.

23. I.L. Al-Qadi, S. Zhao, P. Shangguan, Railway ballast fouling detection using GPR data: introducing a combined time-frequency and discrete wavelet techniques, Near Surf. Geophys. 14 (2) (2016) 145-153.

24. I.L. Al-Qadi, W. Xie, R. Roberts, Scattering analysis of ground-penetrating radar data to quantify railroad ballast contamination, NDT \& E Int. 41 (6) (2008) 441-447.

25. H. Jol, “Ground Penetrating Radar”, Book, Ed. Elsevier, 2009.

26. D. Li, J. Hyslip, T.R. Sussmann, S. Chrismer, Railway geotechnics, Ed. Taylor and Francis, 2015.

27. T.R. Sussmann, M. Ruel, S. Christmer, Sources, influence, and criteria for ballast fouling condition assessment. In: Proceeding of the 91st Annual Meeting of the Transportation Research Board, 11 pp, 2012.

28. F. Tosti, C. Patriarca, E.C. Slob, A. Benedetto, S. Lambot, Clay content evaluation in soils through GPR signal processing, J. Appl. Geophys. 97 (2013) 69-80.

29. F. Tosti, A. Benedetto, L. Bianchini Ciampoli, S. Lambot, C. Patriarca, E.C. Slob, GPR analysis of clayey soil behaviour in unsaturated conditions for pavement engineering and geoscience applications, Near Surf. Geophys. 14 (2) (2016) 127-144.

30. B. Indraratna, L.J. Su, C.A. Rujikiatkamjorn, A new parameter for classification and evaluation of railway ballast fouling, Can. Geotech. J., 48 (2) (2011) 322-326.

31. N. Tennakoon, B. Indraratna, C. Rujikiatkamjorn, S. Nimbalkar, T. Neville, The role of ballast-fouling characteristics on the drainage capacity of rail substructure, Geotech. Test. J., 35 (4) (2012) 1-12.

32. L. Pajewski, F. Tosti, W. Kusayanagi, Antennas for GPR Systems, Chapter 2 - Civil Engineering Applications of Ground Penetrating Radar, Springer Transactions in Civil and Environmental Engineering Book Series, 41-67, 2015.

33. R. Roberts, I. Al-Qadi, E. Tutumluer, J. Boyle, and T.R. Sussmann, Advances in Railroad Ballast Evaluation Using $2 \mathrm{GHz}$ Horn Antennas, in Proc. 11th International Conference on Ground Penetrating Radar, Columbus, OH., USA, 2006.

34. ASTM D6087-08, “Standard Test Method for Evaluating Asphalt-Covered Concrete Bridge Decks Using Ground Penetrating Radar,” ASTM International, West Conshohocken, PA, 2008.

35. J.S. Mundrey, Railway track engineering, Tata McGraw-Hill Education Ed., 2009.

36. F. Benedetto, F. Tosti, A signal processing methodology for assessing the performance of ASTM standard test methods for GPR systems, Signal Processing, 132 (2017) 327-337. 
37. EN 13286-2:2005, "Unbound and hydraulically bound mixtures - Part 2: Test methods for the determination of the laboratory reference density and water content - Proctor compaction. European Committee for Standardization, 2015.

38. R.Wu, J. Li, Z.S. Liu, Super resolution time delay estimation via MODEWRELAX. IEEE Aero. Elec. Sys. 35 (1) (1999) 294-307.

39. J. Redman, J. Davis, L. Galagedara, G. Parkin, Field studies of GPR air launched surface reflectivity measurements of soil water content, in Proc. of the 9th International Conference on Ground Penetrating Radar (GPR 2002), Santa Barbara, California, USA, 2002, art. no. 4758, pp. 156-161.

40. J.R. Birchak, C.G. Gardner, J.E. Hipp, J.M. Victor, High dielectric constant microwave probes for sensing soil moisture. Proceedings of the IEEE 62, (1974) 93-102.

41. K., Lichtenecker, K. Rother,: Die herleitung des logarithmischen mischungsgesetzes aus allgemeinen prinzipien der stätionaren strömung. Phys. Z. (1931) 32 255-260.

42. K. Roth, R. Schulin, H. Fluhler, W. Attinger, Calibration of time domain reflectometry for water content measurement using composite dielectric approach, Water Resour. Res. 26 (1990) 2267-2273

43. A. Brovelli, G. Cassiani, Effective permittivity of porous media: a critical analysis of the complex refractive index model, Geophys. Prospect. 56 (2008) 715-727.

44. C. Patriarca, F. Tosti, C. Velds, A. Benedetto, S. Lambot, E.C. Slob, Frequency dependent electric properties of homogeneous multi-phase lossy media in the ground-penetrating radar frequency range, J. Appl. Geophys. 1(97) (2013) 81-88.

45. W. E. Fensler, E. F. Knott, A. Olte, K. M. Siegel, The electromagnetic parameters of selected terrestrial and extraterrestrial rocks and glasses, The moon, (Kopal, Z., and Mikhailov, Z.K., Ed) IAU Symposium 14, 545-565.

46. M.C. Forde, R. De Bold, G. O’Connor, J.P. Morrissey, New analysis of Ground Penetrating Radar testing of a mixed railway trackbed, Transportation Research Board Annual Meeting, 2010.

47. A. Benedetto, A. Umiliaco, Evaluation of hydraulic permeability of open-graded asphalt mixes using a full numerical simulation, J. Mater. Civil Eng. 26 (4) (2014) 599-606.

48. K.S. Kunz, R.J. Luebbers, The Finite Difference Time Domain Method for Electromagnetics”, CRC Press, 1993.

49. A. Taflove, Computational Electrodynamics: The Finite-Difference Time-Domain Method, Artech House, 1995.

50. K.S. Yee, Numerical solution of initial boundary value problems involving Maxwell's equations in isotropic media, IEEE T. Antenn. P. 14 (1966) 302-307.

51. A. Giannopoulos, Modelling ground penetrating radar by GprMax, Constr. Build. Mater. 19 (10) (2005) 755-762. 
52. A. Benedetto, F. Tosti, L. Bianchini Ciampoli, L. Pajewski, D. Pirrone, A. Umiliaco, M.G. Brancadoro, A simulationbased approach for railway applications using GPR, in Proceedings of the 2016 International Conference of Ground Penetrating Radar, Hong Kong, 13-16 June, 2016. 